\title{
Examining the Relationship among Gender, Generation, Language and Acculturation Levels on Latino Leaders in the U.S.
}

\author{
Karina Gil, Ph.D., MSW \\ Interim Director and Assistant Professor \\ Worden School of Social Services \\ Our Lady of the Lake University \\ United States
}

\section{Introduction}

The exponential growth of the Latino population in the United States has triggered dramatic changes at all levels of society. Latinos are the largest minority group in the United States at 55.4 million representing $17.4 \%$ of the total population (U.S. Census, 2015). They are also a very diverse group with $63 \%$ being Mexican Americans, 9.2\% being Puerto Rican, 3.5\% being Cuban, 2.8\% being Dominican, $7.9 \%$ being Central American, 5.5\% being South American, and 6.8\% being all other Hispanics (U.S. Census Report, 2011).

Although there is a long way to go for Latinos to be fully represented in leadership positions, a few have been able to reach the upper echelons. According to a study conducted by the Hispanic Association on Corporate Responsibility (2009), Hispanics represent 6\% of 384 open board positions. Another study conducted by U.S. Senator Robert Menendez (D-NJ) (2010), found that Hispanics comprise 3.28\% of board members and 2.90\% on executive teams, which is about one-fifth of the $15 \%$ they represent in the U.S. population. When it comes to Latino leaders in politics, out of the estimated 511, 000 elected officials in the U.S. (Lewis, 2012), 2,500 are Latino officials in various levels of the political arena at the local and national level (Andrade, 2008, p. 1). There is a plethora of scholarly research on the impact of acculturation on Latinos. However, limited research has been done on those Latinos who achieve leadership levels and acculturation.

\section{Acculturation}

There is little consensus among scholars regarding the definition of acculturation. The term was first proposed by anthropologist McGee (1898) and Mead (1932) as they used it to describe interchanges between indigenous cultures and dominant cultures. Later, after being tasked by The Social Science Council, Redfield, Linton, and Herskovitz updated the definition to reflect the interchange that occurs when two cultures come into contact with each other. They defined it as the phenomena that results when groups of individuals having different cultures come into continuous first-hand contact that results in subsequent changes in the original culture patterns of either or both groups. More traditional, and somewhat controversial definitions, described acculturation as a continuous process in which a culture, after coming into contact with another, moves from a native or tradition-oriented state through a transitional stage to an elite acculturated stage (Spindler \& Spindler, 1967). Later, Berry (1980) defined acculturation as a four-step process that included assimilation, integration, separation and marginalization. A more recent definition provided by Clark and Hofsess (1998), explains acculturation as a process on an individual level that focuses on members of one group adopting the cultural patterns of the majority or host culture, and highlights the fact that acculturation focuses on the impact that the two cultures have on each other.As the study of acculturation has progressed, scholars are adopting bi-dimensional and multi-dimensional perspectives of understanding in which it is acknowledged that the dominant culture may also undergo a change process influenced by the non-dominant culture (Richman, Gaviria, Flaherty, Birz, \& Wintrob, 1987;Mendoza 1984;Sodowsky, Lai, \&Plake, 1991; Zambrana, Scrimshaw, Collins, \& Dunkel-Schetter, 1997).

\section{Acculturation and Latinos}

Latinos are caught between two worlds: their culture of origin and the dominant U.S. culture. As such, and depending on how long they have been in the U.S., they experience different degrees of exposure to the two large cultural systems over their lifespan and learn to integrate different aspects of these cultural systems (Cuéllar, Siles \& Bracamontes, 2004). Thus, the acculturation level affects every aspect of job performance and leadership experience. 


\section{Acculturation, Language and Generation}

Language is an important component of acculturation. Latinos tend to be more acculturated when they speak English and their families have been in the U.S. for multiple generations (Tran, 2010). A study conducted by the Pew Hispanic Center in collaboration with the Kaiser Family Foundation (2002) found that Latinos who primarily speak English and those, whose families have been in the United States for multiple generations, tend to have social values that are more characteristic of mainstream American views than are the views of Latino immigrants. Another study conducted by the Pew Hispanic Center (2012) found that most Hispanics are bilingual or use Spanish, but use of English rises through the generations that have been in the U.S. Interestingly, they also found that Hispanics believe in the importance of learning English, but they also expressed a desire for future generations of U.S. Hispanics to speak Spanish.

Additionally, a study conducted by Hakimzadeh and Cohn (2007) found that 44\% of all Latino adults, both foreign born and native born, are comfortable speaking in both English and Spanish. They outnumbered the $41 \%$ of Hispanic adults who speak mainly Spanish, as well as the $15 \%$ who describe themselves as largely English speakers.

\section{Acculturation, Generation and Gender in the Latino Community}

Latino women represent roughly $48 \%$ of the Latino population (Pew Hispanic Center, 2008). Most studies regarding acculturation have seldom looked at gender or specifically, Latina leaders. Instead, they have concentrated on the relationship between genders. Acculturation was found to be positively related to more liberal views about women and negatively related to feminine role-type behavior in Mexican-American women (Kranau, Green \& Valencia-Weber, 1982). Generation also plays a role. Studies found that second-generation Puerto Rican women were less likely to endorse stereotypical gender roles and also reported more assertive behaviors than firstgeneration women (Soto, 1983; Soto \& Shaver, 1982). Additionally, when it comes to views about the workplace, more acculturated Mexican American women tended to be less supportive of traditional roles for women in the workplace and at home than Mexican American men (Gowen \& Trevino, 1998).

In summary, there has been a plethora of research that examined the relationship between generation, language and acculturation on Latinos. However, limited research has included women and Latino leaders in the study of acculturation. The purpose of this research is to examine the relationship among gender, generation, language and acculturation levels on Latino leaders in the U.S.

\section{Method}

\section{Participants}

The number of participants consisted of $(\mathrm{N}=188)$ in which 87 were females, 100 were males, and one person's gender was unknown. All participants self-identified as Latino or Hispanic and held leadership positions. Regarding race, most participants identified their race as White $(n=94)$ at $56.6 \%$. Participants in this study were highly educated with the majority holding a Master's degree $(n=64)$ at $34.2 \%$, followed by a Bachelor's degree $(n$ $=62)$ at $33.2 \%$ and a Doctoral degree $(n=21)$ at $11.2 \%$. Their average income was $(M=\$ 95,229.44)$. Most participants self-identified as being third generation or higher $(n=55)$ at $30.1 \%$, and most participants indicated that they were fully bilingual $(n=113)$ at $60.4 \%$. Regarding leadership positions, most participants indicated they held upper management positions: President $(n=46)$ at28.2\%, Vice-President $(n=15)$ at 9.2\%, Director $(n=39)$ at $23.9 \%$, Owner $(n=6)$ at $3.7 \%$, Manager/Supervisor $(n=36)$ at $22.1 \%$. Most participants indicated that they were working in the non-profit sector $(n=73)$ at $41 \%$, followed by Education $(n=29)$ at $16.3 \%$, Health Care $(n=$ $18)$ at $10.1 \%$, Entrepreneur/Small Business Owner $(n=25)$ at $14 \%$, Industrial/Manufacturing/Research Facility $(n$ $=17)$ at $9.6 \%$, Government/Military $(n=14)$ at $7.9 \%$, Construction $(n=2)$ at $1.1 \%$, and there were some that did not report their industry $(n=10)$.

\section{Instruments}

The Short Acculturation Scale for Hispanics (Marin, et al., 1987)was used to measure acculturation levels. Respondents rated 12 items in five-point Likert-type scales to evaluate the extent to which the respondent engages in behaviors related to the culture of origin (Hispanic) or the host American culture. Three factors were evaluated: language use and ethnic loyalty, media, and ethnic social relations. Acculturation was rated from a score of one to five, in which a score from one to 2.99 is considered as "less acculturated", while a score from three to five is 
considered as "more acculturated". This instrument was selected because it has been validated for use with all Hispanics groups, and it has an internal consistency of .92 in all items.

The Short Acculturation Scale for Hispanics was available for public use via a web-enabled anonymous survey tool. Additionally, participants completed a researcher-created demographic survey.

\section{Procedures}

For this exploratory, cross-sectional quantitative study, participants were attained through formal and informal contacts. Through the formal contact route, participants from the National Council of La Raza leadership, management and affiliate executive directors were recruited. Through the informal contact route, participants were recruited by informal networking with local and national Latino organizations and Latino-targeting/serving organizations, and by using professional networking sites and blogs. Participants were directed to complete the surveys through an internet site.

A consent form, which provided information about the research, including potential benefits and risks, and ensured anonymity with a confidentiality statement, was presented to the participant, who was prompted and required to give the participant's agreement prior to taking the surveying instruments. The principal investigator was granted permission to conduct the survey by the university's Internal Review Board (IRB) Committee and was responsible for the collection of the survey responses.

\section{Results}

\section{Overall Acculturation Scores}

The acculturation mean score of the group was $(M=3.42)$, which indicates that this was an acculturated group. However, a more detailed analysis found surprising results. When each acculturation factor of Language Use and Ethnic Loyalty, Media and Ethnic Social Relations were analyzed individually, the results indicated that the group was less acculturated on the factor of Ethnic Social Relations $(M=2.67)$, since a score of 2.99 is used to differentiate between less acculturated (score from 1 to 2.99) to more acculturated (score from 2.99 to 5). Thus, indicating that this group of Latino leaders tended to socialize with those if the same ethnic group. Figure 1 illustrates the study group's mean scores for acculturation.

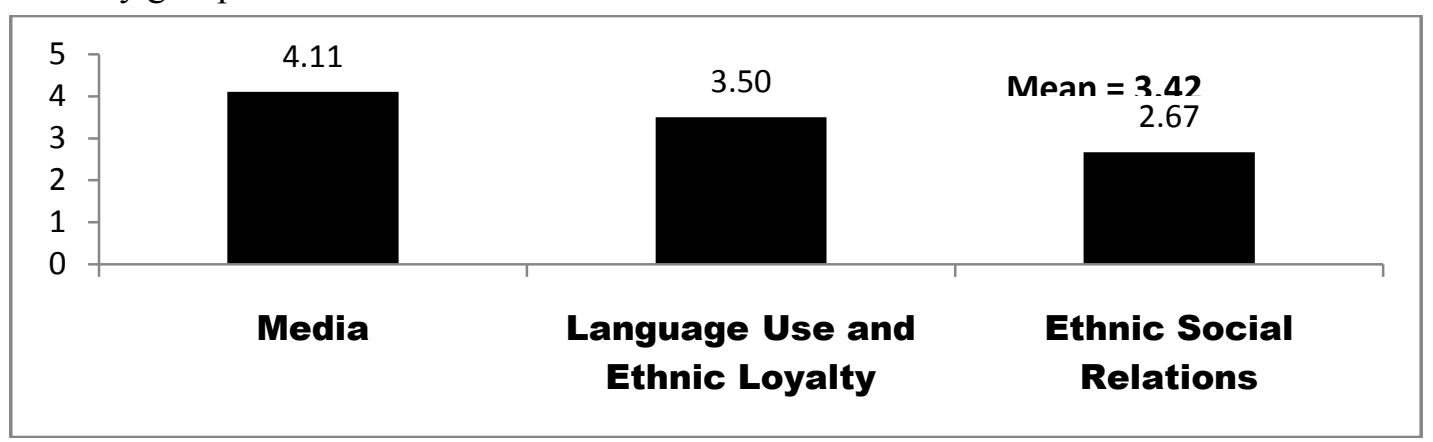

Figure 1. Bar graph of mean scores of Study Sample on the Three Acculturation Factors Analysis of Gender, Generation, Language and Acculturation

A multi-variate analysis of variance was conducted with the three independent variables of gender, generation and language spoken at home and the three acculturation factors as dependent variables. Although there are several overall statistical tests available, Wilks's Lambda had the desirable characteristics of robustness and statistical power. The Wilks's Lambda value for generation was .735, with $p=.000$. The Wilks's Lambda value for language use was .686, with $p=.000$ as illustrate on Table 1. After this overall finding of significance, three one-way ANOVAs were conducted. The results indicated a significant main effect for Generation and Language Use and Ethnic Loyalty $\mathrm{F}(3)=12.555, \mathrm{p}=.000$ and Generation and Media $\mathrm{F}(3)=5.731, \mathrm{p}=.001$ as illustrated on Table 2 . The results of a LSD post hoc analysis indicated that Recent Immigrant $(M=2.73)$ and First Generation $(M=$ 3.26) scores were less acculturated on the factor of Language Use and Ethnic Loyalty than Second Generation ( $M$ $=3.71)$ and Third Generation or Higher $(M=4.22)$ as illustrated on Figure 2. 


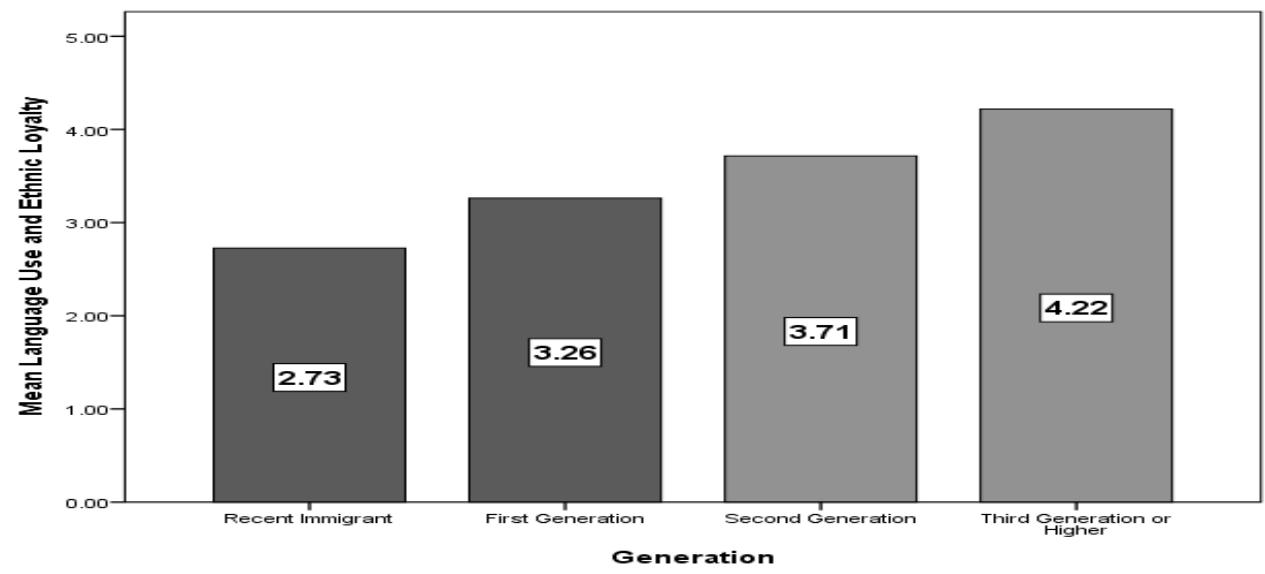

Figure 2. Bar graph for Generation and Language Use and Ethnic Loyalty

Table 1MANOVA on Gender, Generation and Language Spoken at Home and the Three Acculturation Factors

\begin{tabular}{llll}
\hline Effect & Value & F & Sig. \\
\hline Gender & .992 & .373 & .773 \\
Generation & .735 & 5.210 & .000 \\
Language spoken at home & .686 & 9.900 & .000 \\
Gender*Generation & .939 & 1.020 & .424 \\
$\begin{array}{l}\text { Gender*Language spoken at home } \\
\text { Generation*Language spoken at }\end{array}$ & .937 & 1.575 & .154 \\
home & .946 & .666 & .784 \\
$\begin{array}{l}\text { Gender*Generation*language spoken } \\
\text { at home }\end{array}$ & .949 & .630 & .816 \\
\hline
\end{tabular}

Table 2: Three One-Way ANOVA for Generation and Language Spoke at Home on three Acculturation Factors

\begin{tabular}{|l|l|l|l|l|l|l|}
\hline Source & Dependent Variable & $\begin{array}{l}\text { Type III } \\
\text { Sum of } \\
\text { Squares }\end{array}$ & df & $\begin{array}{l}\text { Mean } \\
\text { Square }\end{array}$ & F & Sig. \\
\hline \multirow{4}{*}{ Generation } & $\begin{array}{l}\text { Language Use and Ethnic } \\
\text { Loyalty }\end{array}$ & 13.045 & 3 & 4.348 & 12.555 & .000 \\
\cline { 2 - 7 } & Media & 7.685 & 3 & 2.562 & 5.731 & .001 \\
\cline { 2 - 7 } & Ethnic Social Relations & .398 & 3 & .133 & .330 & .804 \\
\hline \multirow{2}{*}{$\begin{array}{l}\text { Language } \\
\text { Spoken at Home }\end{array}$} & $\begin{array}{l}\text { Language Use and Ethnic } \\
\text { Loyalty }\end{array}$ & 18.958 & 2 & 9.479 & 27.369 & .000 \\
\cline { 2 - 7 } & Media & 1.832 & 2 & .916 & 2.049 & .133 \\
\cline { 2 - 7 } & Ethnic Social Relations & 2.966 & 2 & 1.483 & 3.680 & .028 \\
\hline
\end{tabular}

Additionally, three one-way ANOVAs were conducted for language spoken at home and Language Use and Ethnic Loyalty and language use and Ethnic Social Relations. The results indicated a significant main effect for language spoken at home and Language Use and Ethnic Loyalty $\mathrm{F}(2)=27.369, \mathrm{p}=.000$ and language spoken at home and Ethnic Social Relations $\mathrm{F}(2)=3.680, \mathrm{p}=.028$ as previously illustrated on table 2 . The results of a LSD Post Hoc analysis indicated that Spanish Only $(M=1.91)$ and Bilingual $(M=3.17)$ scores were less acculturated on the factor of Language Use and Ethnic Loyalty than English Only $(M=4.27)$ as illustrated on Figure 3. Another LSD Post Hoc analysis also indicated that Spanish Only $(M=2.18)$ and Bilingual $(M=2.61)$ scores were less acculturated on the factor of Ethnic Social Relations than English Only $(M=2.85)$ as illustrated on Figure 4. 


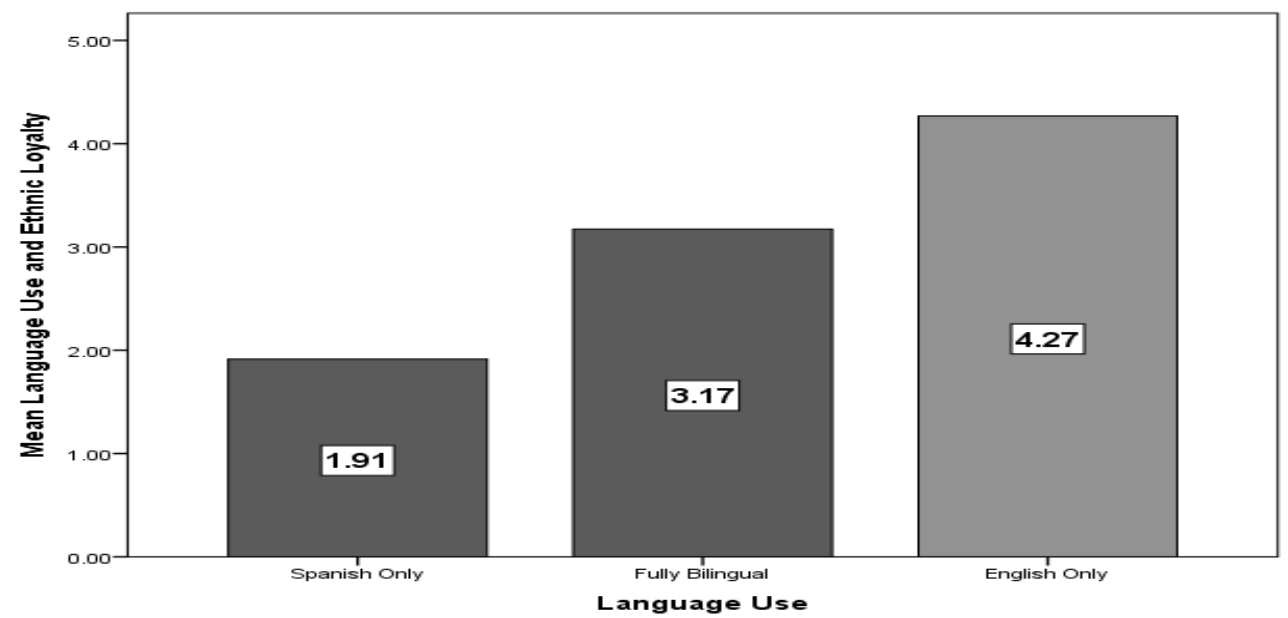

Figure 3. Bar graph on Language Spoken at Home and Language Use and Ethnic Loyalty

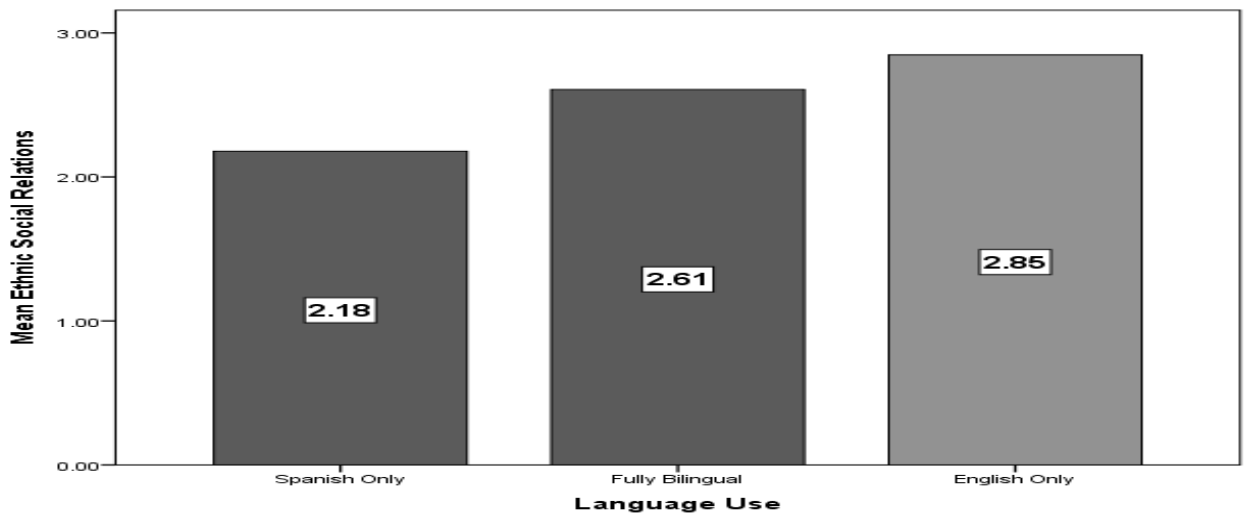

Figure 4. Bar graph of Language Spoken at Home and Ethnic Social Relation

\section{Discussion}

Based on the demographic results of scoring the SASH for this group, results indicate that the study sample composed of national Latino leaders preferred to socialize with members of their own ethnic group. A possible explanation for this result is that most of the participants of this study indicated they worked for non-profit organizations that tended to be Latino serving institutions. Therefore, a simple explanation may be that there is simply no opportunity to socialize outside of their ethnic group. This may also point to the lack of ethnic diversity in their place of employment. Generation was found to have a statistical effect on the acculturation factors of Language Use and Ethnic Loyalty and Media. Further analysis indicated that recent immigrants and first generations were less acculturated on the factor of Language Use and Ethnic Loyalty than second and third generations or higher, which indicate that they maintained and used their native language more. This is consistent with the findings of the literature that indicates that people born outside of the United States had a negative relationship with English language (Teneyuca, 2005). Additionally, recent immigrants and second generations were also found to be less acculturated on the factor of Media which is consistent with previous findings of this study that indicated that the participants who were less acculturated on language use had as a consequence a lesser preference for the English language. This finding directly impacts the language the individual prefers when accessing the Media. This finding also seems to be in line with the literature that indicates that Latino youth tend to be more acculturated to the U.S. mainstream culture when they speak English and their families have been in the U.S. for multiple generations (Pew Hispanic Center \& Kaiser Family Foundation, 2004). However, it is important to indicate that all instruments utilized in this research where provided in English, and the fact that a portion of the participants indicated their preference for the Spanish language media, may point to ethnic loyalty and personal preference even when they speak English. 
Language use was found to have a statistical effect on the acculturation factors of Language Use and Ethnic Loyalty and Ethnic Social Relations. Statistical analysis indicated that Spanish Only and Bilingual speakers were less acculturated on the factor of Language Use and Ethnic Loyalty. Being proficient in both Spanish and English provides an opportunity for individuals to converse in the language of their choice, thus making them less willing to speak English exclusively. It is important to point out that the mean difference between the Spanish-Only group was $(M=1.91)$ which was significantly lower than the Bilingual group $(M=3.17)$. According to the scoring of the Short Acculturation Scale for Hispanic, the Spanish-Only group would be considered as less acculturated and the Bilingual group would be considered as more acculturated. Language use was found to have a statistical effect on the acculturation factors of Ethnic Social Relations. The statistical analysis indicated that Spanish Only and Bilingual speakers were less acculturated on the factor of Ethnic Social Relations than English only speakers. This finding is interesting in the fact that all applied instruments were provided in English only therefore it can be inferred that those who selected Spanish Only are in away battling with their own acculturation process and choosing to socially engage with those of their own ethnic group. This is especially significant since language use is very much tie to ethnic loyalty and identity. Miranda and White (1993) found that Hispanics with stronger loyalty towards the Hispanic culture had lower social interest regarding other groups, and found a strong positive correlation between cultural loyalty and social interest.

Leadership scholars argue that leaders, due to their very roles, are responsible for making decisions that help their organizations adapt and succeed in competitive dominant environments (e.g., Bass, 1991; Waldman \& Yammarino, 1999). Therefore, it could have been hypothesized, that the mere fact of the leadership position, which implies higher educational level, acculturation and language use, will cause Latino leaders to be fully acculturated to the main culture. However, based on the results of this present research, Latino leaders do not seem to score too different from the rest of the Latino population and their acculturation level continues to be heavily impacted by generation and language. Also, as previously indicated, just like the rest of the Latinos, Latino leaders do prefer to interact socially with members if their own group. It is important to note that in this study gender was not found to be significant, which seems to indicate that Latina leaders are not too different than their male counterpart regarding acculturation.

\section{Limitation of the Findings}

The limitations of the study included a sample of convenience which limits the generalizability of the results. Most of the data were self-reported, which can be affected by self-perceptions, and most research participants worked in the non-profit sectors. Additionally, most of the data were self-reported, which can be affected by selfperceptions, and most research participants worked in the non-profit sectors. Finally, all the questionnaires were administered in English only, which limited the participants to those who were English speakers leaving behind an important percentage of community leaders who are Spanish speakers only.

\section{Implication and Recommendation for Future Research}

The Latino community is the fastest growing minority group in the United States and as such, its members are increasingly moving into leadership positions. Unfortunately, very limited research has been done to learn more about Latino leaders and acculturation. The present research attempted to contribute to the body of knowledge and bring to light the uniqueness of Latino leaders and acculturation. The findings indicate that this is not a very different group within the Latino community, but more research is needed. A key factor for level of acculturation was found in the study. Overall, the study sample was acculturated and being bilingual was the driving force behind it. This may, in part, explain the group's success in achieving high level positions in their organizations. Aspiring Latino leaders must strive to be fully bilingual because it provides them with means to navigate different cultures within the Latino and non-Latino communities, and with a competitive advantage.

Interestingly, the research group was less acculturated on the Ethnic Social Relations factor which looks at the ethnicity of the people they socialize with. Aspiring Latino leaders are encouraged to expand their social and professional networks to include other diverse groups and act as a sort of ambassador. This in turn, will provide them with increased cultural competence and wider opportunities for themselves and for their community. The results of this study can have major implications when considering the Latino leadership experience as it relates to language, gender and acculturation. Aside from personal responsibilities, organizations should consider providing more opportunities for multi-ethnic social gatherings and promote expanding relationships outside of personal groups. 
Additionally, when it comes to cross-cultural communication, organization will do well by acknowledging, respecting and promoting bilingualism not only with establish Latino leaders but also with potential leaders.

\section{References}

Andrade, J. (2008). The almanac of Latino politics (4th ed.). Chicago, IL: United States Hispanic Institute.

Bass, B. M. (1991). Bass and Stogdill's handbook of leadership: Theory, research and managerial applications. New York: The Free Press

Berry, J. (1980). Acculturation as variety of adaptation. In A. Padilla (Ed.), Acculturation: Theory, models and some new findings (pp. 9-25). Boulder, CO: Westview.

Berry, J. (1986) Acculturation: Theory, models and some new findings. London: Sage. 9-25.

Clark, L \& Hofses, L. (1998). Acculturation. In Loue, S. (Ed). Handbook of immigrant health (37-59). New York, NY: Plenum Press.

Cuellar, I., Siles, R. I., \& Bracamontes, E. (2004). Acculturation: A psychological construct of continuing relevance to Chicano/a Psychology. In R. J. Velasquez, L. M. Arellano, \& B.

W. McNeil (Eds.), Handbook of Chicano/a Psychology and mental health (pp. 23-42).

Doug, L. (November $9^{\text {th }}, 2012$ ). Local officials must remain in control of elections. The New York

Times. Retrieved from http://www.nytimes.com/roomfordebate/2012/11/08/does-our-voting-system-need-to-befixed/local-officials-must-remain-in-control-of-elections

Hakimzadeh, S. \& Cohn, D. (2007). English usage among Hispanic in the United States. Pew Hispanic Center. Retrieved from http://pewhispanic.org/files/reports/82.pdf

Hispanic Association on Corporate Responsibilities. (2009). 2009 HARC corporate inclusion index. Retrieved fromhttp://www.hacr.org/docLib/20091216_2009CorpInclusionIndex.pdf

Gowan, M., \& Trevino, M., (1998). An examination of gender differences in Mexican American attitudes toward family and career roles. Sex Roles, 38, 1079-1093.

Kranau. E., Green, V., \& Valencia-Weber, G. (1982). Acculturation and the Hispanic women: Attitudes toward women, sex role attribution, sex role behavior, and demographics. Hispanic Journal of Behavioral Science, 4, 21-40.

Marín, G., Sabogal, F., VanOss Marín, B., Otero-Sabogal, F., Pérez-Stable, E. (1987). Development of a short acculturation survey scale for Hispanics. Hispanic Journal of Behavioral Sciences, 9, 183-205.

McGee, M. (1898). Piratical acculturation. American Anthropologist, 11, $243-249$.

Mead, M. (1932). The changing culture of an Indian tribe. New York: Columbia University Press.

Mendoza, R. (1984). Acculturation and sociocultural variability. In J. L. Martinez \& R. Mendoza (Eds.), Chicano Psychology ( $2^{\text {nd }}$ ed., pp, 61-75). Orlando: Academic Press.

Menendez, R. (2010). Corporate diversity report. Retrieved from http://menendez.senate.gov/imo/media/doc/CorporateDiversityReport2.pdf

Miranda, A. \& White, P. (1993). The relationship between acculturation level and social interest among Hispanic adults. Individual Psychology Journal of Adlerian Theory, Research and Practice, 49, 76-85.

Pew Hispanic Center/Kaiser Family Foundation. (2002). National Survey of Latino. Retrieved from http://pewhispanic.org/files/reports/15.pdfPew Hispanic Center. (2004). Assimilation and Language. (Survey Brief). Retrieved fromhttp://pewhispanic.org/files/factsheets/11.pdf

Pew Hispanic Center/Kaiser Family Foundation. (2004). National Survey of Latinos: Education. Retrieved from http://pewhispanic.org/files/reports/25.pdf

Pew Hispanic Center. (2007). English usage among Hispanics in the United States. (Report). Retrieved from http://www.pewhispanic.org/2007/11/29/english-usage-among-hispanics-in-the-united-states/

Pew Hispanic Center. (2008). Hispanic women in the United States 2007. (Fact Sheet)Retrieved from http://pewhispanic.org/files/factsheets/42.pdf

Pew Hispanic Center. (2012). When labels don't fit: Hispanics and their views of identity. Retrieved from http://www.pewhispanic.org/files/2012/04/PHC-Hispanic-Identity.pdf

Redfield, R., Linton, R., \& Herskovits, M. (1936). Memorandum for the study of acculturation. American Anthropologist, 38, 149-152.

Richman, J., Gaviria, M., Flaherty, J., Birs, S., \& Wintrob, R. (1987). The process of acculturation: Theoretical perspectives and an empirical investigation in Peru. Social Science Medicine, 25, 839-847. 
Sodowsky, G., Lai, E., \& Plake, B. (1991). Moderating effects of social cultural variables on

acculturation attitudes of Hispanics and Asian Americans. Journal of Counseling Development, 70, 1941002.Soto, E. (1983). Sex-role traditionalism and assertiveness in Puerto Rican women living in the United States. Journal of Community Psychology, 11, 346-354.

Soto, E., \& Shaver, P. (1982). Sex role traditionalism, assertiveness, and symptoms of Puerto Rican women living in the United States. Hispanic Journal of Behavioral Science. 4, 1-19.

Spindler, L., \& Spindler, G. (1967). Male and female adaptation in culture change: Menomini. In R. Hunt (Ed.), Personalities and Cultures (pp. 56-78). New York: Natural History Press.

Teneyuca, D. (2005). A study of the relationship between leadership style and language preference. Ph.D. dissertation. San Antonio, TX: Our Lady of the Lake University.

Tran, V. (2010). English gain vs. Spanish loss? Language assimilation among second second-generation Latinos in young adulthood. Social Forces, 89(1), 257-284.

U.S. Census Bureau.(2011). The Hispanic population: 2010.2010 Census Brief. Retrieved from http://www.census.gov/prod/cen2010/briefs/c2010br-04.pdfU.S. Census Bureau. (2015). Fact Finder. Retrieved from http://factfinder.census.gov/faces/tableservices/jsf/pages/productview.xhtml?src=bkmk

Waldman, D. A., \& Yammarino, F. J. (1999). CEO charismatic leadership: Levels-of-management and levels-ofanalysis effects. Academy of Management Review, 24, 266-285.

Zambrana, R. E., Scrimshaw, S.C. M., Collins, N. \& Dunkel-Schetter, C. (1997). Prenatal health behaviors and psychological risks factors in pregnancy in women of Mexican origin: the role of acculturation 